\title{
Walking Towards a Healthy Brain and Mind
}

\section{Art F. Kramer}

Northeastern University

\begin{abstract}
The presentation will focus on recent research from our laboratories that has examined the effects of exercise training interventions and physical activity on cognitive and brain health. I will discuss research that has examined changes in brain structure and/or function along with behavioral measures of cognition in interventions lasting from several weeks to 1 year. Study populations will include children, young and middle-aged individuals, and the elderly in addition to a variety of patient groups. Although the focus will be on training to improve cardiorespiratory fitness I will also briefly cover resistance training and well as multi-modal cognitive and exercise training program. Finally, the presentation will identify gaps in the literature and potential solutions.
\end{abstract}

Arthur Kramer is the Director of the Center for Cognitive and Brain Health and professor of Psychology at Northeastern University in Boston. He previously served as Senior Vice Provost for Research and Graduate Education at Northeastern University. He also served as the Director of the Beckman Institute for Advanced Science \& Technology and the Swanlund Chair and Professor of Psychology and Neuroscience at the University of Illinois. He received his Ph.D. in Cognitive/ Experimental Psychology from the University of Illinois. Professor Kramer's research projects include topics in Aging, Cognitive Psychology, Cognitive Neuroscience, and Human Factors. A major focus of his labs recent research is the understanding and enhancement of cognitive and neural plasticity across the lifespan. He is a former Associate Editor of Perception and Psychophysics and is currently a member of six editorial boards. Professor Kramer is also a fellow of the American Psychological Association, American Psychological Society, a former member of the executive committee of the International Society of Attention and Performance, and a recipient of a NIH Ten Year MERIT Award. He has recently served on the President's Council of Advisors on Science \& Technology (PCAST), the National Academy of Medicine's (NAM) committee on Cognitive Aging, the Chair of the National Academy of Sciences (NAS) workshop on Understanding Pathways to Successful Aging: Behavioral and Social Factors Related to Alzheimer's Disease, the Global Council on Brain Health, and a multitude of other national and international committees. Professor Kramer's research has been featured in a long list of print, radio and electronic media including the New York Times, Wall Street Journal, Washington Post, Huffingtion Post, Chicago Tribune, CBS Evening News, Today Show, National Public Radio and Saturday Night Live.

Professor Kramer's journal articles can be accessed at: https://internal.psychology.illinois.edu/reprints/index.php?site_id=9 